\title{
Safety Assessment Model of Earth-Rock Dam Based on Ideal Point-Cloud Theory
}

\author{
Han Liwei ${ }^{1, *}$, Liu Mingkai ${ }^{1}$, Zhang Hongyang ${ }^{1}$, Yao Liang ${ }^{2}$ and Ge Wei ${ }^{3}$ \\ ${ }^{1}$ College of Water Conservancy, North China University of Water Resources and Electric Power, Zhengzhou 450046, China \\ ${ }^{2}$ Center of Construction Management \& Quality \& Safety Supervision, Ministry of Water Resources, Beijing 100038, China \\ ${ }^{3}$ Faculty of Technology, Policy and Management, Delft University of Technology, Delft 2628 BX, the Netherlands
}

Received 12 June 2019; Accepted 5 August 2019

\begin{abstract}
Uncertainty is inevitable in the safety monitoring and evaluation process of earth-rock dam. Such uncertainty makes the accurate reflection of the running status of earth-rock dams of traditional safety assessment results impossible. Thus, this study proposed a safety assessment model of earth-rock dams based on the combination weighting method of ideal point and the cloud theory model. The proposed model was used to scientifically solve the uncertainty during the safety assessment of earth-rock dams. Real and reliable weights of indexes were determined using the combination weighting method based on the ideal point. Then, the safety evaluation grade ranges of each evaluation index were divided on the basis of the measured data. These grade ranges were "softened" by combining cloud theory. The proposed safety assessment model was applied to an earth-rock dam in the reservoir of a pumped storage station in Tai' an City, Shandong Province, China. Results demonstrate that: (1) the proposed model can effectively solve fuzzy and random problems during the safety assessment of earth-rock dams, and (2) the results show that the safety of the investigated earth-rock dam is in a normal running state. This outcome reflects the actual conditions of the earth-rock dam. The proposed model provides references in the diagnosis and decision making in the earth-rock dam management department.
\end{abstract}

Keywords: Earth-rock dam, Ideal point, Combination weighting method, Cloud theory, Safety assessment

\section{Introduction}

China possesses more than 98,000 reservoir dams, which is the highest number in the world. Approximately $95 \%$ of these dams are earth-rock ones, and most of which are old dams constructed in the 1980s. Several dams have low safety or design standards due to historical reasons and economic and technological conditions at that time. After years of running without repair, approximately $1 / 3$ of these dams encounter numerous potential risks and aging diseases. Such conditions influenced the engineering benefits and even threaten the life and property safety of the citizens downstream. The state and performance of earth-rock dams are continuously changing under various external forces due to complicated natural conditions. Dams are facing different degrees of aging, diseases, and cracks with time due to artificial factors in the material performance and construction process. The safe operations of dams may be affected and may even cause disastrous accidents, such as dam breach, under serious conditions due to the delayed diagnosis of these defects or hidden risks. The safety of earth-rock dams must be tested and evaluated, possible anomalies must be determined, and measures must be adopted by using effective technical means to repair and control structural damages.

The safe operation and management of reservoir dams and their safety monitoring data are full of uncertainties due to the following reasons: 1) The service conditions of dams

*E-mail address: Hanliwei@ncwu.edu.cn

ISSN: 1791-2377 @ 2019 School of Science, HHU. All rights reserved.

doi:10.25103/iestr.124.05 are complicated, and their diseases, such as deformation, seepage, and stress, are reflected in many aspects; 2) Dams have extremely complicated structure. A dam's body has many material zones, strong nonlinearity, and great discreteness. Material parameters change during the operation of engineering projects; 3) Dam safety is influenced by hydrological, meteorological, geological, and construction conditions, terrain, and running management. These influencing factors continuously change $[1,2,3]$. The aforementioned analysis suggests that such uncertainties determine the difference between the safety assessment of dams from that of a general structure. Thus, the safety assessment method for earth-rock dams must be accurate and able to scientifically solve these uncertainty factors.

\section{State of the art}

Traditional safety assessment methods for earth-rock dams are divided into two main types. In the first type, the monitoring and detection data of single monitoring indexes, such as deformation and seepage, are analyzed. Then, many mathematical monitoring models are constructed by using mathematical and mechanical methods to safely assess and monitor dams. The health conditions of earth-rock dams are analyzed and monitored on the basis of the obtained models. Ding et al. [4] performed a finite element analysis on the basis of a 300-m ultrahigh core-wall rock-fill dam in China. In the finite element analysis, stress-deformation characteristics, such as dam body stress, arch effects in central core, deformation distribution of the dam body, excess water pressure distribution in central core, and 
Han Liwei, Liu Mingkai, Zhang Hongyang, Yao Liang and Ge Wei/

Journal of Engineering Science and Technology Review 12 (4) (2019) 38 - 50

horizontal stress distribution on the dam body, were summarized. Chen et al. [5] investigated the structural safety performance of Dashixia concrete faced rock-fill dam based on a large triaxial test and detailed finite element numerical analysis of dam materials. Rashidi et al. [6] conducted a 2D numerical analysis on the largest cross section of the Gavoshan Dam and evaluated its behavior and status during construction and the first impounding using measured and inverse analysis data obtained through finite difference method. Min et al. [7] performed a 3D inverse analysis, simulated the running state of dam, and evaluated the dam safety based on the dam stress, deformation, and seepage observation data of the dam body. However, this type of safety assessment method cannot timely reflect the running state of earth-rock dams. Instead, a certain hysteresis exists. Although monitoring the effects are superficially independent, certain connections exist among different monitoring effects, such as deformation, seepage, and stress, thereby causing difficulty in the accurate diagnosis of the health conditions of earth-rock dam by using the aforementioned method. The second type of assessment method considers earth-rock dam as a system model of the combined actions of all evaluation indexes. The detection data of different evaluation indexes are analyzed using an optimization algorithm for safety assessment. Wei et al. [8] established a performance function of dam hidden trouble deformation and abnormal deformation using artificial neural network and statistical model. Then, they analyzed the safety reliability and sensitivity of dams based on reliability theory and concluded that temperature influenced the probability of potential and abnormal deformations of reservoirs more than the reservoir water level. Liu et al. [9] developed a novel combined model for dam deformation prediction using the gray model and the back-propagation neural network model to achieve the purpose of real-time diagnosis of the dam. Li et al. [10] constructed a dam safety assessment model by combining Adaptive Boosting algorithm and BP neural network. This model can effectively reduce network error and increase network convergence speed. This type of method can realize rapid assessment under the assistance of a computer but neglects the uncertainties in earth-rock dam assessment, thereby resulting in error between assessment results and actual situations.

Many associated studies have solved the uncertainty problems in the safety assessment of earth-rock dams and obtained assessment results that reflect the running state of earth-rock dams. Currently, uncertainty problems in the safety assessment of earth-rock dams are mainly solved using fuzzy set theory. Kucukali [11] applied fuzzy logics in hydropower safety assessment and classified the safety risks of hydropower engineering into several grades according to logical reasoning results. $\mathrm{Fu}$ et al. [12] analyzed the probability of earth-rock dam breach through an event tree analytical method based on fuzzy set theory and verified the method's validity by combining examples. Peng et al. [13] constructed a safety assessment method of earth-rock dams based on multilayer fuzzy evaluation under the assistance of fuzzy mathematics and analytic hierarchy process (AHP) theory. Zheng et al. [14] investigated the risk identification of dams based on fuzzy AHP and the cross entropy of the interval-valued intuitionistic fuzzy sets and recognized the main factors that influence the safety of earth-rock dams. Ji et al. [15] discussed the safety of a hydropower station and calculated the objective weights of different safety assessment indexes using entropy weight method. They also determined the risk level of the hydropower station using the fuzzy technique according to its similarity to an ideal solution. However, the fuzzy set fails to solve the uncertainty. In particular, the fuzzy set abandons randomness and only reflects fuzziness when investigating uncertainties that contain fuzziness and randomness. Thus, the fuzzy set cannot effectively solve uncertainty problems in the safety assessment of earth-rock dams.

In this study, a safety assessment model for earth-rock dams is constructed by combining cloud theory [16] and the combination weighting method based on ideal point. The model can reasonably and completely solve uncertainty problems and determine the accurate weights of evaluation indexes. Cloud theory considers fuzziness and randomness. Likewise, the proposed model can fully reflect fuzziness and randomness in earth-rock dams based on the dual uncertainty reasoning of the cloud model. The model applies the combination weighting method based on ideal points to avoid shortages of single and traditional weighting methods in determining the real and effective combination weights.

The remainder of this study is organized as follows. Section 3 establishes the safety assessment model. Section 4 discusses the applicability of the method through case studies, and finally, the conclusions are summarized in Section 5.

\section{Methodology}

\subsection{Determining the weights of evaluation indexes}

The operational state of earth-rock dam is reflected by using the monitoring and inspection data at different measuring points on distinct positions for various purposes [17]. Numerous evaluation indexes that influence the operational state of the dam must be considered in the safety assessment of earth-rock dams. However, determining the subjective and objective weights of different indexes and reasonably combining them are key problems. At present, the main subjective weighting methods include AHP and best-worst multi-criteria decision-making method $[18,19]$. The calculated subjective weight mainly reflects the importance of evaluation indexes and is not influenced by index values. The main objective weighting methods include entropy weight [20], data envelopment analysis [21], and criteria importance through intercriteria correlation [22]. The objective weight is calculated by the actual values of evaluation indexes and is influenced by the numerical values of the indexes. Generally, the objective weight of the evaluation indexes cannot directly reflect the importance of the indexes. In this study, we calculate the combined weights by using the combination weighting method based on ideal points.

\subsubsection{Determining subjective weights based on improved AHP (IAHP)}

Thomas L. Saaty [23] proposed the AHP theory in 1990. When the evaluation system involves many indexes, a consistency test must be continuously performed to the judgment matrix. This approach requires heavy calculation loads. In the calculation process, the judgment matrix may have poor consistency and even fail the consistency test, thereby making the determination of subjective weights difficult. IAHP [24] was utilized to resolve this issue. This method with self-adjustment feature, more reasonable scale value, and higher judgment transmission compared with the 
Han Liwei, Liu Mingkai, Zhang Hongyang, Yao Liang and Ge Wei/

Journal of Engineering Science and Technology Review 12 (4) (2019) 38 - 50

traditional AHP method, thereby resulting in more accurate calculated weights.

The basic steps of the IAHP method are introduced as follows. Experts with experiences are encouraged to incorporate the evaluation indexes in the safety assessment system of earth-rock dams in an order according to relative importance $x_{1} \geq x_{2} \geq \cdots \geq x_{n}$. The judgment matrix is represented by Eq. (1), where $t_{i}$ is the scale ratio between indexes $x_{i}$ and $x_{i+1}$. The element values in the judgment matrix are calculated according to transmission.

$$
R=\left[\begin{array}{cccccc}
1 & t_{1} & t_{1} t_{2} & t_{1} t_{2} t_{3} & \cdots & t_{1} t_{2} \cdots t_{n-1} \\
1 / t_{1} & 1 & t_{2} & t_{2} t_{3} & \cdots & t_{2} t_{3} \cdots t_{n-1} \\
1 / t_{1} t_{2} & 1 / t_{2} & 1 & t_{3} & \cdots & t_{3} t_{4} \cdots t_{n-1} \\
1 / t_{1} t_{2} t_{3} & 1 / t_{2} t_{3} & 1 / t_{3} & 1 & \cdots & t_{4} t_{5} \cdots t_{n-1} \\
\vdots & \vdots & \vdots & \vdots & \vdots & \vdots \\
1 / t_{1} t_{2} \cdots t_{n-2} & 1 / t_{2} t_{3} \cdots t_{n-2} & 1 / t_{3} t_{4} \cdots t_{n-2} & 1 / t_{4} t_{5} \cdots t_{n-2} & \cdots & t_{n-1} \\
1 / t_{1} t_{2} \cdots t_{n-1} & 1 / t_{2} t_{3} \cdots t_{n-1} & 1 / t_{3} t_{4} \cdots t_{n-1} & 1 / t_{4} t_{5} \cdots t_{n-1} & \cdots & 1
\end{array}\right]
$$

The judgment matrixes constructed through this matrix are consistent and does not require a consistency test, thereby simplifying the calculation process and its practical applications. The weights are calculated by solving Eq. (2):

$$
\mu_{i}=\sqrt[n]{\prod_{j=1}^{n} r_{i j}} / \sum_{i=1}^{n} \sqrt[n]{\prod_{j=1}^{n} r_{i j}}
$$

where $\mu_{i}$ is the subjective weight of different safety assessment indexes of earth-rock dams, and $r_{i j}$ is the ratio scale of elements $i$ and $j$ in the judgment matrix $R$. The definitions of the evaluation indexes are listed in Table 1.

Table 1. Scales and definitions of the judgment matrix

\begin{tabular}{c|c}
\hline Scale & Definition \\
\hline 1 & Two factors are equally important. \\
1.2 & One factor is slightly more important than the other one. \\
1.4 & One factor is evidently more important than the other one. \\
1.6 & One factor is significantly more important than the other one. \\
1.8 & One factor is absolutely more important than the other one. \\
\hline
\end{tabular}

\subsubsection{Determining objective weights based on entropy} weight method

The concept of "information entropy" was proposed by Shen Nong in 1948. This method measures the uncertainty of a random event and can be regarded as the probability of occurrence of a specific information. Objective weights determined through information entropy can express the intensity of competition among evaluation indexes, and assessment results change with the values of evaluation indexes. Therefore, the entropy weight method can solve several problems that involve big information size and difficult quantization of safety assessment indexes of earthrock dams.

The basic steps of entropy weight method are introduced as follows. The safety evaluation index set $U=\left(u_{1}, u_{2}, \ldots, u_{n}\right)$ of an earth-rock dam is composed of $n$ evaluation indexes of the operational state of the dam, and the assessment set $V=\left(v_{1}, v_{2}, \cdots v_{m}\right)$ consists of $m$ assessments. Section 3.3 states that when $m=5$, the assessment results are normal, basically normal, slightly abnormal, strongly abnormal, and seriously abnormal.
Indexes $\left(u_{i}\right)$ in the safety assessment set are evaluated, through which the primary fuzzy mapping $f\left(u_{i}\right)$ from $U$ to $V$ is obtained. A fuzzy judgment matrix $F[25]$ is constructed on the basis of relevant knowledge on fuzzy transformation manifests.

$F=\left[\begin{array}{cccc}f_{11} & f_{12} & \cdots & f_{1 m} \\ f_{21} & f_{22} & \cdots & f_{2 m} \\ \vdots & \vdots & \cdots & \vdots \\ f_{n 1} & f_{n 2} & \cdots & f_{n m}\end{array}\right]$

The entropy of the evaluation index $i$ is:

$e_{i}=-\frac{1}{\ln m} \sum_{j=1}^{m} f_{i j} \ln f_{i j}$

Specifically, when $f_{i j}=0, f_{i j} \ln f_{i j}=0$. Therefore, the objective weight $\left(\varphi_{i}\right)$ of different indexes is:

$\varphi_{i}=\left(1-\mathrm{e}_{i}\right) /\left(n-\sum_{i=1}^{n} e_{i}\right),\left(0 \leq \varphi_{i} \leq 1, \sum_{i=1}^{n} \varphi_{i}=1\right)$

\subsubsection{Combination weighting method based on ideal point}

The traditional combination weighting method can cause "distortion" in the index weight. The traditional method can neither simultaneously consider the advantages of subjective and objective weights nor determine the real objective combination weights. Therefore, the combination weighting method based on ideal point is applied in this study [26].

The main principle of the combination weighting method based on ideal point is to approach the ideal function as much as possible and calculate the weights of different indexes through the mathematical model. The subjective weights of different indexes that are determined using the IAHP method are represented by $\mu=\left(\mu_{1}, \mu_{2}, \ldots, \mu_{n}\right)$, whereas the objective weights calculated by the entropy weight method are expressed as $\varphi=\left(\varphi_{1}, \varphi_{2}, \ldots, \varphi_{n}\right)$. The combination weights after ideal point weighting are 
Han Liwei, Liu Mingkai, Zhang Hongyang, Yao Liang and Ge Wei/

Journal of Engineering Science and Technology Review 12 (4) (2019) 38 - 50

$\omega=\left(\omega_{1}, \omega_{2}, \ldots, \omega_{n}\right)$. If the ideal weights of different evaluation indexes are recorded $\eta_{j}^{*}=(j=1,2, \ldots, n)$, then the ideal scheme is $A^{*}=\left(x_{1}, x_{2}, \ldots, x_{n}\right)=\left(\omega_{1} \eta_{1}^{*}, \omega_{2} \eta_{2}^{*}, \ldots, \omega_{n} \eta_{n}^{*}\right)$. The distance between the ideal point and scheme $i$ is calculated as:

$$
d_{i}=\left[\sum_{j=1}^{n}\left(y_{i j}-y_{j}^{*}\right)^{2}\right]^{\frac{1}{2}}=\left\{\sum_{j=1}^{n}\left[\left(\eta_{i j}-\eta_{j}^{*}\right) \omega_{j}\right]^{2}\right\}^{\frac{1}{2}}
$$

A small $d_{i}$ value implies that scheme $i$ is close to the ideal scheme. The vectors are unified for the convenience of calculation and expressed as follows:

$$
\begin{aligned}
& \mu^{\prime}=\frac{\mu}{\sqrt{\mu_{1}^{2}+\mu_{2}^{2}+\ldots+\mu_{n}^{2}}} \\
& \varphi^{\prime}=\frac{\varphi}{\sqrt{\varphi_{1}^{2}+\varphi_{2}^{2}+\ldots+\varphi_{n}^{2}}} \\
& \omega^{\prime}=\frac{\omega}{\sqrt{\omega_{1}^{2}+\omega_{2}^{2}+\ldots+\omega_{n}^{2}}}
\end{aligned}
$$

The square of the distance between scheme $A_{i}$ and the ideal point that corresponds to the three weight matrixes, namely, $\mu, \varphi, \omega$, are expressed as:

$$
\begin{aligned}
& d_{i\left(\mu^{\prime}\right)}^{2}=\sum_{j=1}^{n}\left[\left(\eta_{i j}-\eta_{j}^{*}\right) \mu_{j}^{\prime}\right]^{2} \\
& d_{i\left(\varphi^{\prime}\right)}^{2}=\sum_{j=1}^{n}\left[\left(\eta_{i j}-\eta_{j}^{*}\right) \varphi_{j}^{\prime}\right]^{2} \\
& d_{i\left(\omega^{\prime}\right)}^{2}=\sum_{j=1}^{n}\left[\left(\eta_{i j}-\eta_{j}^{*}\right) \omega_{j}^{\prime}\right]^{2}
\end{aligned}
$$

The difference between the weights of combination weighting and subjective and objective weights should be minimized, as shown in Eq. (9).

$$
\begin{aligned}
& f_{\left(\omega^{\prime}\right)}=\left[d_{i\left(\omega^{\prime}\right)}^{2}-d_{i\left(\mu^{\prime}\right)}^{2}\right]^{2}-\left[d_{i\left(\omega^{\prime}\right)}^{2}-d_{i\left(\varphi^{\prime}\right)}^{2}\right]^{2}= \\
& \sum_{j=1}^{n}\left[\left(\eta_{i j}-\eta_{j}^{*}\right)^{2}\left(\omega^{\prime 2}-\mu_{j}^{\prime 2}\right)\right]^{2}+\sum_{j=1}^{n}\left[\left(\eta_{i j}-\eta_{j}^{*}\right)^{2}\left(\omega^{\prime 2}-\varphi_{j}^{\prime 2}\right)\right]^{2}
\end{aligned}
$$

This expression illustrates a problem about an extreme value of the function, and the constraints are:

$$
\left\{\begin{array}{c}
\sum_{j=1}^{n} \omega^{\prime 2}=1 \\
\omega^{\prime}>0, j=1,2, \ldots, n
\end{array}\right.
$$

The extremes of this function are calculated by using a Lagrange function, and the result is expressed as:

$$
\omega^{\prime}=\sqrt{\left(\mu_{j}^{\prime 2}+\varphi_{j}^{\prime 2}\right) / 2} \quad(j=1,2, \ldots, n)
$$

The calculated combination weight is:

$$
\omega_{j}=\omega_{j}^{\prime} / \sum_{j=1}^{n} \omega_{j}^{\prime} \quad(j=1,2, \ldots, n)
$$

\subsection{Cloud theory}

\subsubsection{Basic definition of cloud}

Let $U$ be a quantitative domain expressed in accurate numerical values and $C$ be a qualitative concept on $U$. If the quantitative value $x \in U$, then $x$ is the random implementation of $C$, and the degree of certainty of $x$ to $C$ $(\mu(x) \in[0,1])$ is a random number with a stable trend. $x$ distribution on $U$ is called the cloud, and each $x$ is defined as one cloud drop $(x, \mu(x))$.

The cloud properties are presented as follows:

(1) The random implementation mentioned in the definition is realized under the significance of the probability. The degree of certainty mentioned in the definition not only refers to the membership under the sense of fuzzy set but also to the distribution under the sense of probability. This implementation reflects the correlation between fuzziness and randomness.

(2) For any $x \in U$, the mapping from $x$ to the interval $[0,1]$ is a one-to-more transformation. The degree of certainty of $x$ to $C$ is a probability distribution but not a fixed numerical value.

(3) The cloud is composed of cloud drops that scatter around without order. A cloud drop refers to the primary implementation of the qualitative concept on quantity. A large amount of cloud drops can effectively reflect the overall characteristics of the qualitative concept.

(4) If the probability of occurrence of cloud drops is large and the degree of certainty is high, then the contribution of cloud drops to the concept is high.

\subsubsection{Cloud model}

The cloud model is a qualitative-quantitative exchange model proposed by academician Li Deyi based on the traditional fuzzy mathematics and probability statistics. This model describes "uncertainty" with "uncertainty." Such model not only reflects the randomness in the samples that represent qualitative concept value, but also the fuzziness of membership degree. In addition, this model discloses the correlation between fuzziness and randomness. The cloud model features various forms, such as normal, triangle, semirising, and semi-falling clouds. Among these forms, the normal cloud model is universal [27]. Thus, the normal cloud model is adopted in this study (Fig. 1).

The digital characteristics of the normal cloud model are expressed by three parameters, namely, expectation $(E x)$, entropy $(E n)$, and hyper entropy $(H e)$.

Considering the fuzziness and randomness of the limits of evaluation grades, the calculation formula for zone softening is expressed as: 
Han Liwei, Liu Mingkai, Zhang Hongyang, Yao Liang and Ge Wei/

Journal of Engineering Science and Technology Review 12 (4) (2019) 38 - 50

$$
\left\{\begin{array}{c}
E x=\left(x_{\text {max }}+x_{\text {min }}\right) / 2 \\
E n=\left(x_{\text {max }}-x_{\text {min }}\right) / 2.355 \\
H e=s
\end{array}\right.
$$

where $x_{\max }$ and $x_{\min }$ are the double constraints in each grade, and $s$ represents the values of fuzziness and randomness according to the corresponding indexes.

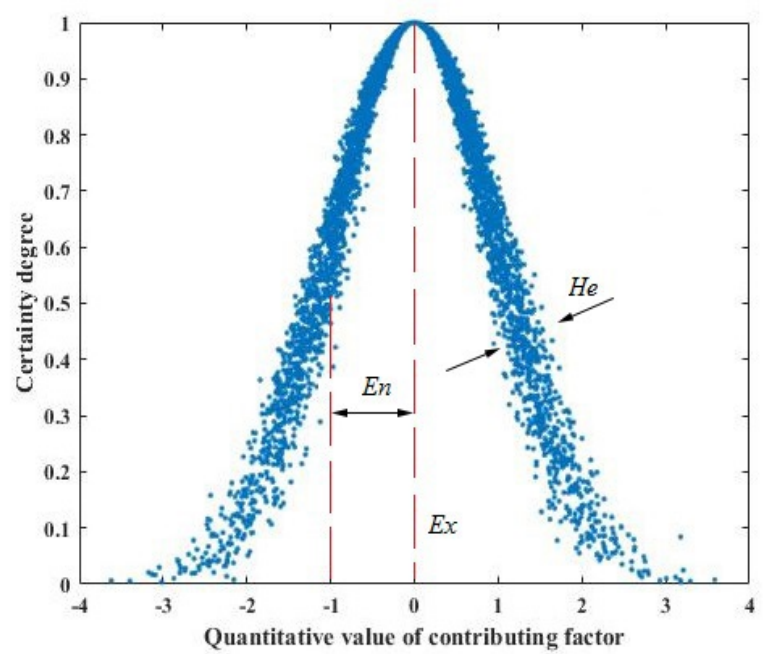

Fig. 1. Normal cloud model
3.3 Safety assessment system for earth-rock dams 3.3.1 Construction of an evaluation index system

The safety operation of an earth-rock dam is the collaborative consequence of the measured data of multiple indexes at different monitoring points in various positions. Consequently, safety conditions in the entire earth-rock dam and its different regions must be investigated for the safety assessment of the dam. The appropriate and direct selection of evaluation indexes determines the reasonability and reliability of the ultimate assessment results. In the assessment system, the final assessment goal is found at the top layer, whereas the basic evaluation indexes are found at the bottom. Membership relations exist between any two layers. The entire evaluation index system presents a multilayer progressive analytical structure. Each layer corresponds to the evaluation index of the upper layer and the assessment goal of the next layer. The purpose, reliability, simplification, quantitative, relative independence, and hierarchical principles are established with comprehensive consideration to evaluation indexes. The evaluation index system is shown in Fig. 2.

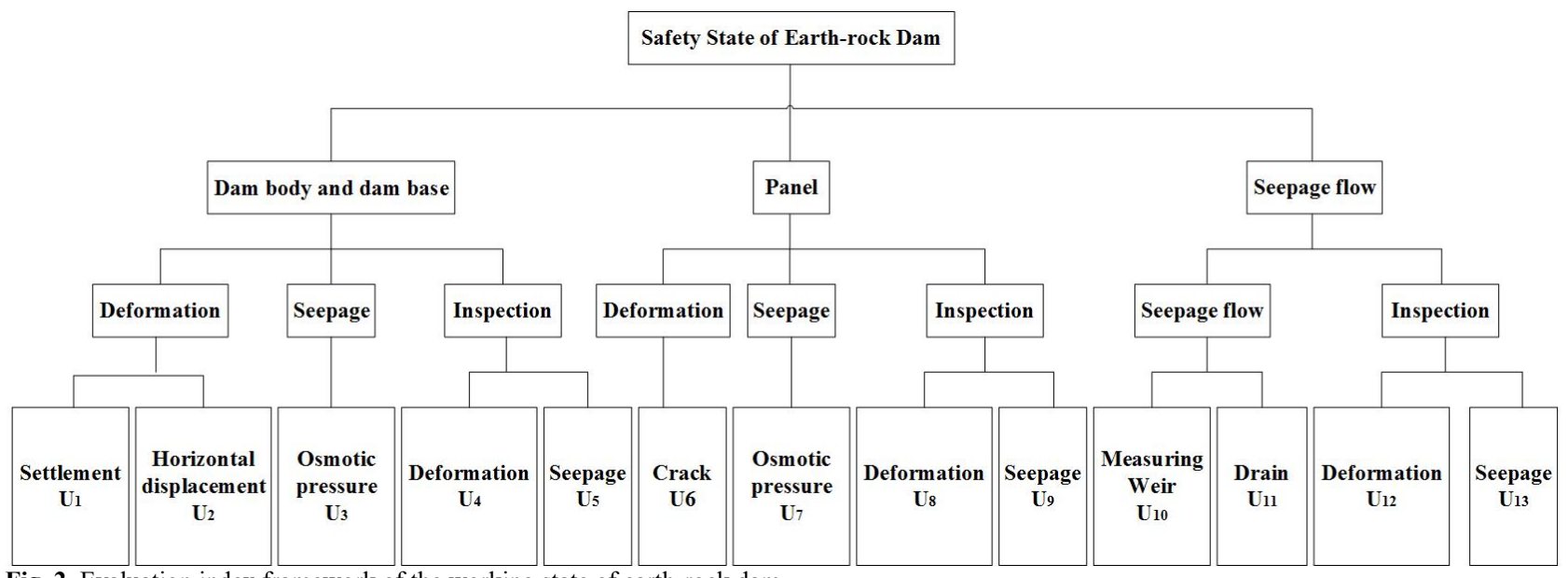

Fig. 2. Evaluation index framework of the working state of earth-rock dam

\subsubsection{Classification of evaluation grades}

Evaluation grade describes whether the safety operation of the dams is "good" or "bad". Nowadays, evaluation standards, namely, "normal", "disease", and "risk" are imperfect. In this study, the evaluation grade is discussed from multiple directions in accordance with the relevant detection norms and rules for the implementation of safety examination of dams $[28,29,30]$, psychological activities of human beings, and practical experiences. The safety of an earth-rock dam is divided into five levels: $X=\left\{X_{1}, X_{2}, X_{3}, X_{4}, X_{5}\right\}=$ \{normal, basically normal, slightly abnormal, strongly abnormal, seriously abnormal $\}$.

\subsubsection{Analysis of quantitative indexes}

\subsubsection{Numerical value of quantitative indexes}

Monitoring index is a numerical limit used to assess if the dam operation is normal and safe. If the measured value is lower or within the regulation range of the monitoring index, then the structural state of the dam is generally normal, and the dam is safe; otherwise, the dam is dangerous. The safety monitoring index of a dam is a dangerous value, which refers to a limit that reflects whether the dam is safe or not. This value is mainly determined according to the numerical value of the effect, which is limited by safety requirements. If the mathematical model is expressed as $\hat{y}=f\left(x_{1}, x_{2}, \ldots, x_{n}\right)$, then the monitoring index can be expressed as $[y]=\hat{y} \pm \varepsilon=f\left(x_{1}, x_{2}, \ldots, x_{n}\right) \pm \varepsilon$, where $[y]$ is the monitoring index limit of the parameter $y, \hat{y}$ is the 
Han Liwei, Liu Mingkai, Zhang Hongyang, Yao Liang and Ge Wei/

Journal of Engineering Science and Technology Review 12 (4) (2019) 38 - 50

statistical estimation value of $y, x_{i}$ is the main environmental factor that influences $y$, and $\varepsilon$ is the confidence bandwidth. When the monitoring indexes are determined, $\varepsilon=p S$, where $p=2-3$ and $S$ is the residual standard deviation of the model expressed as:

$$
S=\sqrt{\frac{\sum_{i=1}^{n}\left(y_{i}-\hat{y_{i}}\right)^{2}}{n-k-1}}
$$

where $n$ is the total number of the measured effects, and $k$ is the degree of freedom of the measured effects.

Thus, $[y]=f\left(x_{1}, x_{2}, \ldots, x_{n}\right) \pm p S$, and the limits of the monitoring indexes can be expressed as $\left[y_{\max }\right],\left[y_{\min }\right]$.

Quantitative index analysis mainly depends on the measured data of different monitoring points. The value of the measured effect $X$ is divided into five zones, which are centered at $\hat{y}$ according to the deviation of the observed values at the upper and lower sides based on Reference [31].

$$
\begin{aligned}
& \text { A zone : }\left[y_{\min }\right] \leq y \leq\left[y_{\max }\right] \text {, } \\
& \text { and } \hat{y}-2 S \leq y \leq \hat{y}+2 S \\
& B \text { zone : }\left[y_{\min }\right] \leq y \leq\left[y_{\max }\right] \text {, } \\
& \text { and } \hat{y}+2 S \leq y \leq \hat{y}+3 S \text { or } \hat{y}-3 S \leq y \leq \hat{y}-2 S \\
& \text { C zone : }\left[y_{\min }\right] \leq y \leq\left[y_{\max }\right] \text {, } \\
& \text { and } y>\hat{y}+3 S \text { or } y<\hat{y}-3 S \\
& D \text { zone : } y>\left[y_{\max }\right] \text { or } y<\left[y_{\min }\right] \text {, } \\
& \text { and } y \leq \hat{y}+3 S \text { or } y \geq \hat{y}-3 S \\
& \text { E zone : } y>\left[y_{\max }\right] \text { or } y<\left[y_{\min }\right] \text {, } \\
& \text { and } y>\hat{y}+3 S \text { or } y<\hat{y}-3 S
\end{aligned}
$$

If the measured value of the observation items is high or small, then the dam is risky. Zoning of $y$ value should be bilaterally considered according to Fig. 3(b) and Eq. (15). If the measured value of the observation items is slightly high, then the dam has safety problems. By contrast, if the measured value of observation items is slightly small, then the dam is safe. Zoning of $y$ value should be unilaterally considered according to Fig. 3(a) and Eq. (16).

$$
\begin{aligned}
& \text { A zone : } y \leq\left[y_{\text {max }}\right] \text {, and } y \leq \hat{y}+2 S \\
& B \quad \text { zone }: y \leq\left[y_{\max }\right] \text {, and } \hat{y}+2 S \leq y \leq \hat{y}+3 S \\
& C \quad \text { zone }: y \leq\left[y_{\text {max }}\right] \text {, and } y>\hat{y}+3 S \\
& D \quad \text { zone : } y>\left[y_{\max }\right] \text {, and } y \leq \hat{y}+3 S \\
& \text { E zone : } y>\left[y_{\max }\right] \text {, and } y>\hat{y}+3 S
\end{aligned}
$$

where $y$ is the statistical estimation value of the monitoring parameter $y ; S$ is the residual standard value; and $\left[y_{\max }\right],\left[y_{\min }\right]$ are the limits of the monitoring indexes.

Five regions (e.g., $A, B, C, D$, and $E$ ), which are divided according to the measured data, correspond to the classification of the evaluation grades. The subordinate functional intervals are divided by using the fuzzy membership method as follows: $X=\left\{X_{1}, X_{2}, \cdots, X_{m}\right\}=$ \{normal, basically normal, slightly abnormal, strongly abnormal, Seriously abnormal $\}=\{[1,0.8],(0.8,0.6],(0.6,0.4]$, $(0.4,0.2],(0.2,0]\}$.

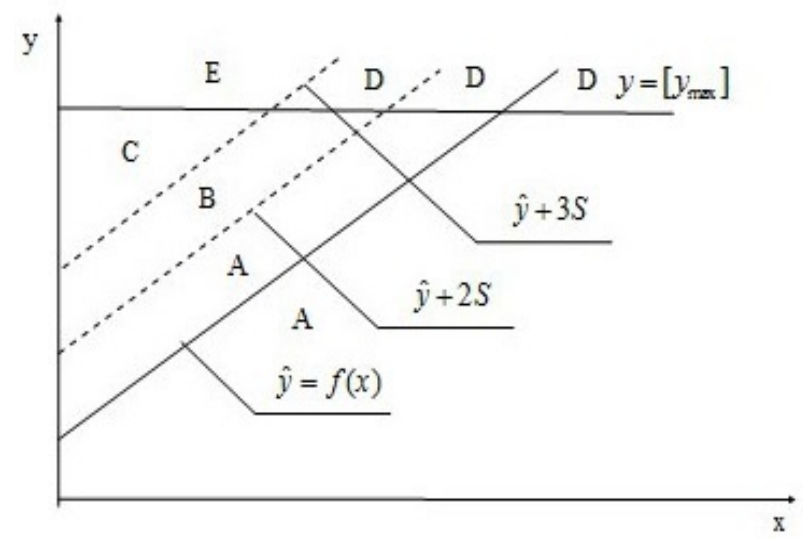

(a) Unilateral situations

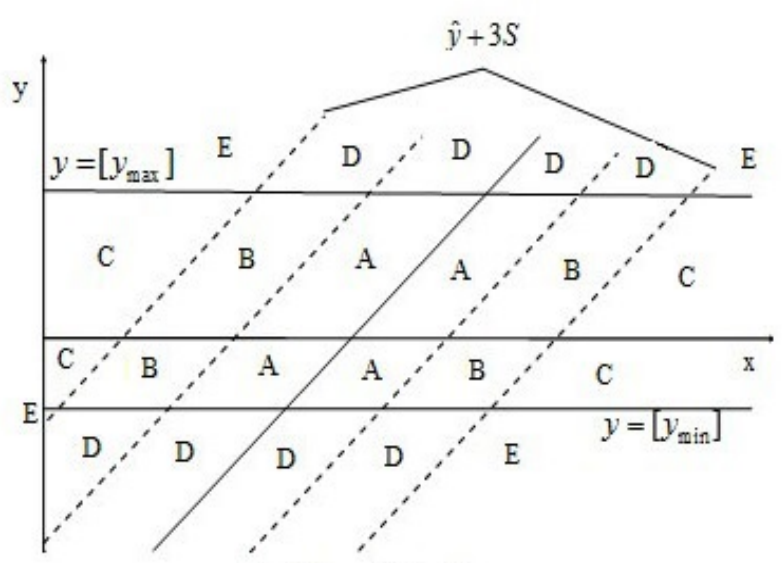

(b) Bilateral situations

Fig. 3. Numerical performance of the quantitative evaluation indicators

\subsubsection{Trends of qualitative indexes}

The trend of change in the evaluation index refers to the variation trend of the measured data of the dam with time. Such change is generally irreversible and is mainly determined by dam material characteristics, soil at dam base, and the dam's body structure. The trend of change in the evaluation index exhibits five expression forms (Fig. 4).

The safety conditions of an earth-rock dam in $T$ periods (or moments) are analyzed, which determines the safety grade $\left(\mathrm{j}_{0}(\mathrm{t})\right)$ and grade eigenvalues $\left(\mathrm{j}^{*}(\mathrm{t})(\mathrm{t}=1,2, \ldots, T)\right)$ in $T$ periods (or moments). The variation trend of $j_{0}(t)-t$ and $j^{*}(t)-t$ can be analyzed on this basis. 
Han Liwei, Liu Mingkai, Zhang Hongyang, Yao Liang and Ge Wei/

Journal of Engineering Science and Technology Review 12 (4) (2019) 38 - 50

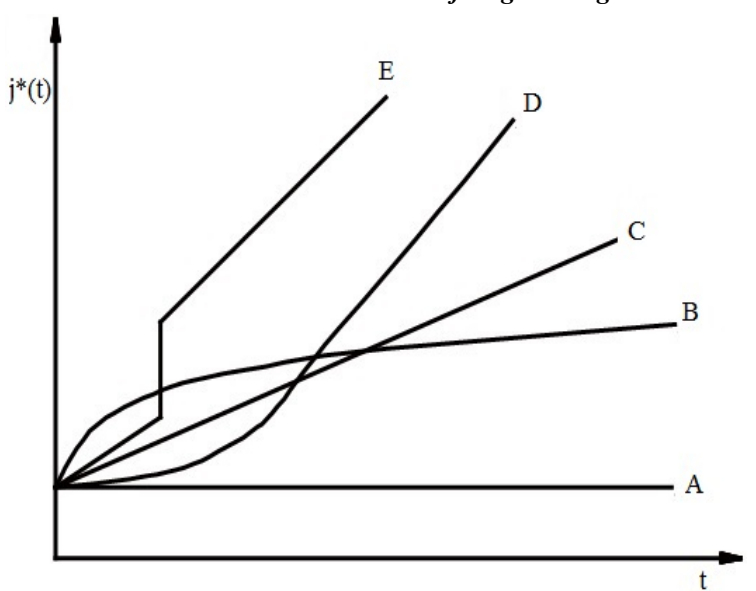

Fig. 4. Trend performance of the quantitative evaluation indicators

(1) Curve A: If $j_{0}(t)$ is low, then $j^{*}(t)$ is basically constant or slightly changes within a small range and does not gradually increase with time $(t)$, indicating the high safety of the earth-rock dam.

(2) Curve B: If $j_{0}(t)$ is relatively low, then $j^{*}(t)$ rapidly increases in the early stage and becomes flat in the operational stage accompanied with a small fluctuation. This outcome is most common in practical engineering and is a relatively normal condition.

(3) Curve C: If $j_{0}(t)$ is relatively low, then $j^{*}(t)$ constantly increases. This outcome suggests that the earthrock dam has potential risks against safety operation.

(4) Curve D: If $j_{0}(t)$ is relatively high, and $j^{*}(t)$ gradually increases with time $t$, then the safety of the earthrock dam is worsening. Thus, monitoring must be strengthened, and the warning level must be increased.
(5) Curve E: If $j_{0}(t)$ is high, and $j^{*}(t)$ continuously increases with sudden surges, then the safety of the earthrock dam is poor, and high attention must be focused on safety monitoring. Moreover, relevant strengthening measures should be adopted in time.

The five zones (e.g., $A, B, C, D$, and $E$ ) in the numerical value and the five curves (e.g., $A, B, C, D$, and $E$ ) in the change trend correspond to five evaluation grades: $X=\left\{X_{1}, X_{2}, X_{3}, X_{4}, X_{5}\right\}$.

\subsubsection{Analysis of qualitative indexes}

Accurately expressing the walkaround inspection information of dam safety by numerical values or mathematical equation is difficult. This information is generally analyzed through pure qualitative description method. This approach is not only inapplicable to the comprehensive evaluation of dam safety but also hinders the development of dam safety monitoring toward automatic data acquisition, data processing modeling, intelligent analysis, visual outcome outputs, and networked data transmission and management. Therefore, a suitable quantitative analysis method for the qualitative index for dam safety evaluation must be developed. The qualitative index values are fuzzy and non-quantitative, making the accurate expression of these values by using precise numbers difficult. However, such values can be quantized using several methods, such as expert scoring and fuzzy membership. In this study, the qualitative indexes are quantized using the former. For instance, for the inspection results for the seepage walkaround inspection item are first constructed Engineering performance and expert-suggested evaluation standards of seepage walkaround inspection on the base of the relevant regulations and norms. Then, it is further quantized by experts. Finally, the seepage of the earth-rock dam base is scored by combining Tables 2 and 3 .

Table 2. Engineering performance and expert-suggested evaluation standards of seepage walkaround inspection

\begin{tabular}{|c|c|c|c|c|c|}
\hline $\begin{array}{c}\text { Seepage } \\
\text { walkaround } \\
\text { inspection of the dam base }\end{array}$ & Normal & Basically normal & $\begin{array}{c}\text { Slightly } \\
\text { abnormal }\end{array}$ & $\begin{array}{l}\text { Strongly } \\
\text { abnormal }\end{array}$ & $\begin{array}{l}\text { Seriously } \\
\text { abnormal }\end{array}$ \\
\hline Scouring of the dam base & No scouring & $\begin{array}{l}\text { Local slight } \\
\text { scouring }\end{array}$ & $\begin{array}{l}\text { Local obvious } \\
\text { scouring }\end{array}$ & Serious scouring & $\begin{array}{l}\text { Very serious } \\
\text { scouring }\end{array}$ \\
\hline Corrosion of the dam body and base & $\begin{array}{l}\text { Seepage water is } \\
\text { clear without } \\
\text { sediments. }\end{array}$ & $\begin{array}{l}\text { Seepage water is } \\
\text { relatively clear } \\
\text { and accompanied } \\
\text { with certain } \\
\text { sediments. }\end{array}$ & $\begin{array}{l}\text { Seepage water is } \\
\text { turbid and has } \\
\text { certain sediments. }\end{array}$ & $\begin{array}{l}\text { Seepage water is } \\
\text { turbid and has a } \\
\text { high sediment } \\
\text { content. }\end{array}$ & $\begin{array}{l}\text { Seepage water is } \\
\text { very turbid, and } \\
\text { the turbidity } \\
\text { continues to } \\
\text { increase. }\end{array}$ \\
\hline Seepage & Small & Low & Moderate & High & Very high \\
\hline Growth of seepage & No growth & Small growth & Growth trend & $\begin{array}{l}\text { Obvious growth } \\
\text { trend }\end{array}$ & $\begin{array}{l}\text { Significant } \\
\text { growth trend }\end{array}$ \\
\hline Drainage facilities & Normal & $\begin{array}{c}\text { Few blockages, } \\
\text { short time }\end{array}$ & $\begin{array}{l}\text { Partial failure, } \\
\text { long time }\end{array}$ & Majority failure & $\begin{array}{l}\text { Long-term } \\
\text { majority failure }\end{array}$ \\
\hline
\end{tabular}

Table 3. Quantitative characteristics of seepage performance in walkaround inspection

\begin{tabular}{|c|c|c|c|c|c|}
\hline Quantitative characteristics of the different elements & $\begin{array}{c}\text { Scouring } \\
\text { intensity }(\%)\end{array}$ & $\begin{array}{c}\text { Corrosion } \\
\text { intensity }(\%)\end{array}$ & $\begin{array}{c}\text { Seepage flow } \\
\text { (L/S) }\end{array}$ & $\begin{array}{c}\text { Growth of } \\
\text { seepage flow } \\
(\%) \\
\end{array}$ & $\begin{array}{c}\text { Failure of } \\
\text { drainage } \\
\text { facilities (\%) }\end{array}$ \\
\hline Normal & 0 & 0 & 5 & 0 & 0 \\
\hline Basically normal & 10 & 10 & 9 & 10 & 10 \\
\hline Slightly abnormal & 40 & 40 & 13 & 40 & 40 \\
\hline Strongly abnormal & 70 & 70 & 17 & 70 & 70 \\
\hline Seriously abnormal & 100 & 100 & 21 & 100 & 100 \\
\hline
\end{tabular}

3.4 Safety assessment model of earth-rock dams

\subsubsection{Cloud model of safety grade limits}

The relevant knowledge in Section 3.3.2 manifests that the operational state of the earth-rock dam is divided into five 
Han Liwei, Liu Mingkai, Zhang Hongyang, Yao Liang and Ge Wei/

Journal of Engineering Science and Technology Review 12 (4) (2019) 38 - 50

grades, namely, "normal," "basically normal," "slightly abnormal," "strongly abnormal," and "seriously abnormal," which correspond to Grades 1-5, respectively. These grades are used to express the safety level of the earth-rock dam.
The safety grade limits of the evaluation indexes are shown in Table 4.

Table 4. Security level limit values for each evaluation indicator

\begin{tabular}{|c|c|c|c|c|c|}
\hline Evaluation indicators & Normal & Basically normal & Slightly abnormal & Strongly abnormal & Seriously abnormal \\
\hline$U_{1}$ & $(0.8,1)$ & $(0.6,0.8)$ & $(0.4,0.6)$ & $(0.2,0.4)$ & $(0,0.2)$ \\
\hline$U_{2}$ & $(0.8,1)$ & $(0.6,0.8)$ & $(0.4,0.6)$ & $(0.2,0.4)$ & $(0,0.2)$ \\
\hline$U_{3}$ & $(0.8,1)$ & $(0.6,0.8)$ & $(0.4,0.6)$ & $(0.2,0.4)$ & $(0,0.2)$ \\
\hline$U_{4}$ & $(80,100)$ & $(60,80)$ & $(40,60)$ & $(20,40)$ & $(0,20)$ \\
\hline$U_{5}$ & $(80,100)$ & $(60,80)$ & $(40,60)$ & $(20,40)$ & $(0,20)$ \\
\hline$U_{6}$ & $(0.8,1)$ & $(0.6,0.8)$ & $(0.4,0.6)$ & $(0.2,0.4)$ & $(0,0.2)$ \\
\hline$U_{7}$ & $(0.8,1)$ & $(0.6,0.8)$ & $(0.4,0.6)$ & $(0.2,0.4)$ & $(0,0.2)$ \\
\hline$U_{8}$ & $(80,100)$ & $(60,80)$ & $(40,60)$ & $(20,40)$ & $(0,20)$ \\
\hline$U_{9}$ & $(80,100)$ & $(60,80)$ & $(40,60)$ & $(20,40)$ & $(0,20)$ \\
\hline$U_{10}$ & $(0.8,1)$ & $(0.6,0.8)$ & $(0.4,0.6)$ & $(0.2,0.4)$ & $(0,0.2)$ \\
\hline$U_{11}$ & $(0.8,1)$ & $(0.6,0.8)$ & $(0.4,0.6)$ & $(0.2,0.4)$ & $(0,0.2)$ \\
\hline$U_{12}$ & $(80,100)$ & $(60,80)$ & $(40,60)$ & $(20,40)$ & $(0,20)$ \\
\hline$U_{13}$ & $(80,100)$ & $(60,80)$ & $(40,60)$ & $(20,40)$ & $(0,20)$ \\
\hline
\end{tabular}

The parameters $\left(E x_{q}, E n_{q}, H e_{q}\right)$ in the standard cloud model of the safety grade limits of different evaluation indexes are calculated using Eq. (13). The calculated results are shown in Table 5. $(q=1-13)$

Table 5. Standard cloud model for the level limit of the safety evaluation index of earth-rock dams

\begin{tabular}{c|c|c|c|c|c}
\hline Evaluation indicators & Normal & Basically normal & Slightly abnormal & Strongly abnormal & Seriously abnormal \\
\hline$U_{1}$ & $(0.9,0.85,0.0008)$ & $(0.7,0.85,0.0008)$ & $(0.5,0.85,0.0008)$ & $(0.3,0.85,0.0008)$ & $(0.1,0.85,0.0008)$ \\
$U_{2}$ & $(0.9,0.85,0.0008)$ & $(0.7,0.85,0.0008)$ & $(0.5,0.85,0.0008)$ & $(0.3,0.85,0.0008)$ & $(0.1,0.85,0.0008)$ \\
$U_{3}$ & $(0.9,0.85,0.0008)$ & $(0.7,0.85,0.0008)$ & $(0.5,0.85,0.0008)$ & $(0.3,0.85,0.0008)$ & $(0.1,0.85,0.0008)$ \\
$U_{4}$ & $(90,8.5,0.0004)$ & $(70,8.5,0.0004)$ & $(50,8.5,0.0004)$ & $(30,8.5,0.0004)$ & $(10,8.5,0.0004)$ \\
$U_{5}$ & $(90,8.5,0.0004)$ & $(70,8.5,0.0004)$ & $(50,8.5,0.0004)$ & $(30,8.5,0.0004)$ & $(10,8.5,0.0004)$ \\
$U_{6}$ & $(0.9,0.85,0.0008)$ & $(0.7,0.85,0.0008)$ & $(0.5,0.85,0.0008)$ & $(0.3,0.85,0.0008)$ & $(0.1,0.85,0.0008)$ \\
$U_{7}$ & $(0.9,0.85,0.0008)$ & $(0.7,0.85,0.0008)$ & $(0.5,0.85,0.0008)$ & $(0.3,0.85,0.0008)$ & $(0.1,0.85,0.0008)$ \\
$U_{8}$ & $(90,8.5,0.0004)$ & $(70,8.5,0.0004)$ & $(50,8.5,0.0004)$ & $(30,8.5,0.0004)$ & $(10,8.5,0.0004)$ \\
$U_{9}$ & $(90,8.5,0.0004)$ & $(70,8.5,0.0004)$ & $(50,8.5,0.0004)$ & $(30,8.5,0.0004)$ & $(10,8.5,0.0004)$ \\
$U_{10}$ & $(0.9,0.85,0.0008)$ & $(0.7,0.85,0.0008)$ & $(0.5,0.85,0.0008)$ & $(0.3,0.85,0.0008)$ & $(0.1,0.85,0.0008)$ \\
$U_{11}$ & $(0.9,0.85,0.0008)$ & $(0.7,0.85,0.0008)$ & $(0.5,0.85,0.0008)$ & $(0.3,0.85,0.0008)$ & $(0.1,0.85,0.0008)$ \\
$U_{12}$ & $(90,8.5,0.0004)$ & $(70,8.5,0.0004)$ & $(50,8.5,0.0004)$ & $(30,8.5,0.0004)$ & $(10,8.5,0.0004)$ \\
$U_{13}$ & $(90,8.5,0.0004)$ & $(70,8.5,0.0004)$ & $(50,8.5,0.0004)$ & $(30,8.5,0.0004)$ & $(10,8.5,0.0004)$ \\
\hline
\end{tabular}

\subsubsection{Calculation of cloud membership}

The cloud membership between the evaluation indexes and the safety grades are calculated according to the following steps.

(1) The value that correspond to each evaluation index is considered a cloud drop $x$.

(2) Table. 5 illustrates that the digital characteristics of the standard cloud models of the safety grade limits are obtained $\left(E x_{q}, E n_{q}, H e_{q}\right)$.
(3) The random number $E n^{\prime}$ that obeys $N\left(E n_{q}, H e_{q}^{2}\right)$ is generated.

(4) The values of different evaluation indexes and membership among various grades are calculated according to Eq. (17).

$c=e^{-\frac{\left(x-E x_{q}\right)^{2}}{2\left(E n^{\prime}\right)^{2}}}$

(5) Repeat Steps 1-4 for $n$ folds, and the mean is used as the final cloud membership $(n=1000)$. 
Han Liwei, Liu Mingkai, Zhang Hongyang, Yao Liang and Ge Wei/

Journal of Engineering Science and Technology Review 12 (4) (2019) 38 - 50

The calculated cloud membership values are used to form the cloud membership matrix $(C)$ of the evaluation indexes.

$$
C=\left[\begin{array}{ccccc}
c_{11} & c_{12} & c_{13} & c_{14} & c_{15} \\
c_{21} & c_{22} & c_{23} & c_{24} & c_{25} \\
\vdots & \vdots & \vdots & \vdots & \vdots \\
c_{n 1} & c_{n 2} & c_{n 3} & c_{n 4} & c_{n 5}
\end{array}\right]
$$

Where $c_{i j}$ is the cloud membership between the evaluation index $\left(U_{i}\right)$ and the cloud model of the safety grade $j(j=1,2$, $3,4,5)$; and $n$ is the number of evaluation indexes $(n=13)$. Variable $j$ is the evaluation grade and is set as an integer within 1-5.

\subsubsection{Determination of the safety grade}

The safety assessment model of earth-rock dam based on ideal point-cloud theory can be calculated as follows:

$R_{k}=C \times W$

where $R_{k}$ is the comprehensive cloud membership; and $C$ and $W$ are the cloud membership and combination weight matrixes of the evaluation index, respectively.

The comprehensive cloud membership can be obtained using the aforementioned equation. Subsequently, the state eigenvalues of the safety grades of earth-rock dams are calculated according to the following equation:

$R^{\prime}=\sum_{k=1}^{m} k R_{k} / \sum_{k=1}^{m} R_{k}$

where $R^{\prime}$ denotes the state eigenvalues of the grade, and $k$ represents the evaluation grades $(k=1,2,3,4,5)$.

The digital characteristics of the normal cloud are calculated according to the concepts in Section 3.2. The conceptual cloud model of the evaluation grades is constructed, and the membership cloud of $R^{\prime}$ is obtained. The membership cloud of $R^{\prime}$ is compared with the conceptual cloud model of the evaluation grades, thereby obtaining the final assessment results (Fig. 5).

\section{Result analysis and discussions}

\subsection{Brief introduction to the project}

The earth-rock dam reservoir of Tai'an pumped storage power station is located in Tai' an City, Shandong Province, China. This dam uses reinforced concrete face rock-fill dam (CFRD) with a maximum height of $413.80 \mathrm{~m}$. The normal storage level of the reservoir is $410.00 \mathrm{~m}$ with a total reservoir volume of $11,681,000 \mathrm{~m}^{3}$. The observational instruments were installed in the dam's body to monitor dynamic changes and working performance during the dam operation

The distribution of the observational instruments is shown in Figs. 6-9.

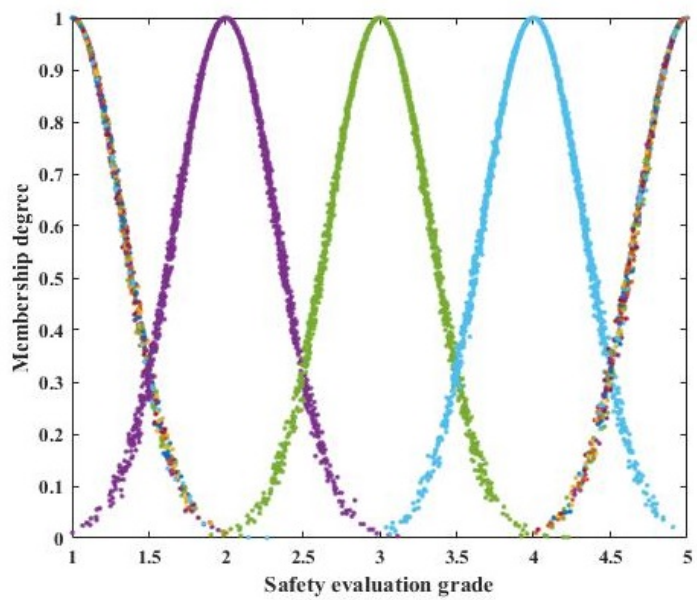

Fig. 5. Cloud atlas of the evaluation grade

\subsection{Case study}

The operational state evaluation of the earth-rock dam (Fig. 1) involves many indexes. However, due to space limitation, only the "dam body and dam base" in Fig. 1 were thoroughly calculated and analyzed.

The monitoring indexes at different measuring points for dam deformation and seepage were analyzed according to Section 3.3. The monitoring indexes for the appearance subsidence deformation of "dam body and dam base" are presented in Table 6. The other monitoring indexes are not listed here due to space limitation.

The measured data of the studied dam in October 2016 were analyzed according to Section 3.3. The safety degrees of the evaluation indexes of "dam body and dam base" can be obtained, as shown in Table 7 .

The evaluation indexes of the "dam body and dam base" comprised five factors, namely, settlement $\left(U_{1}\right)$, horizontal displacement $\left(U_{2}\right)$, osmotic pressure $\left(U_{3}\right)$, deformation ( $\left.U_{4}\right)$, and seepage $\left(U_{5}\right)$. Relevant data and experts' suggestions indicated that the importance of these five indexes can be arranged as: $U_{1}>U_{3}>U_{2}>U_{4}>U_{5}$. The relative importance of the five indexes is as follows: $r_{12}=1.1$, $r_{23}=1.3, \quad r_{34}=1.6$, and $r_{45}=1.2$. The subjective and objective weights of different indexes were combined according to the combination weighting method based on ideal points to obtain the combination weight of indexes (Table. 8). 
Han Liwei, Liu Mingkai, Zhang Hongyang, Yao Liang and Ge Wei/

Journal of Engineering Science and Technology Review 12 (4) (2019) 38 - 50

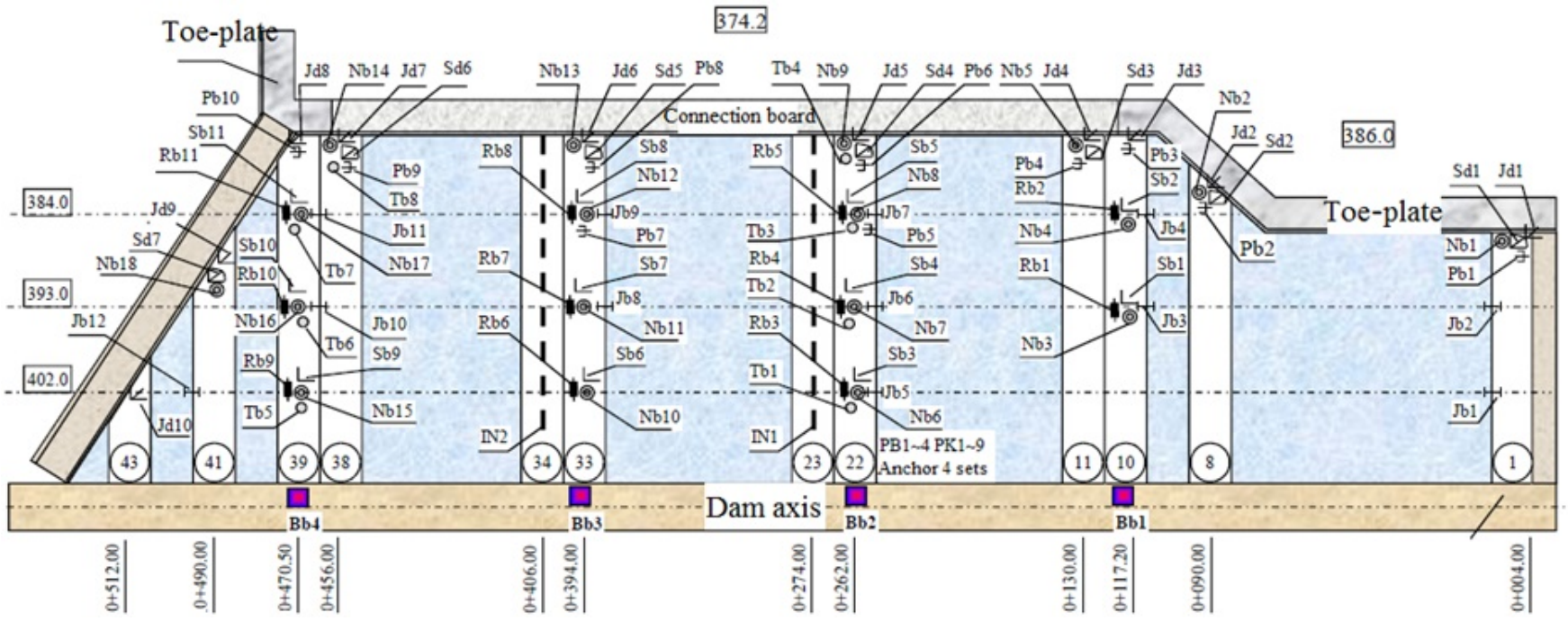

Fig. 6. Distribution of observational instruments on the reinforced CFRD

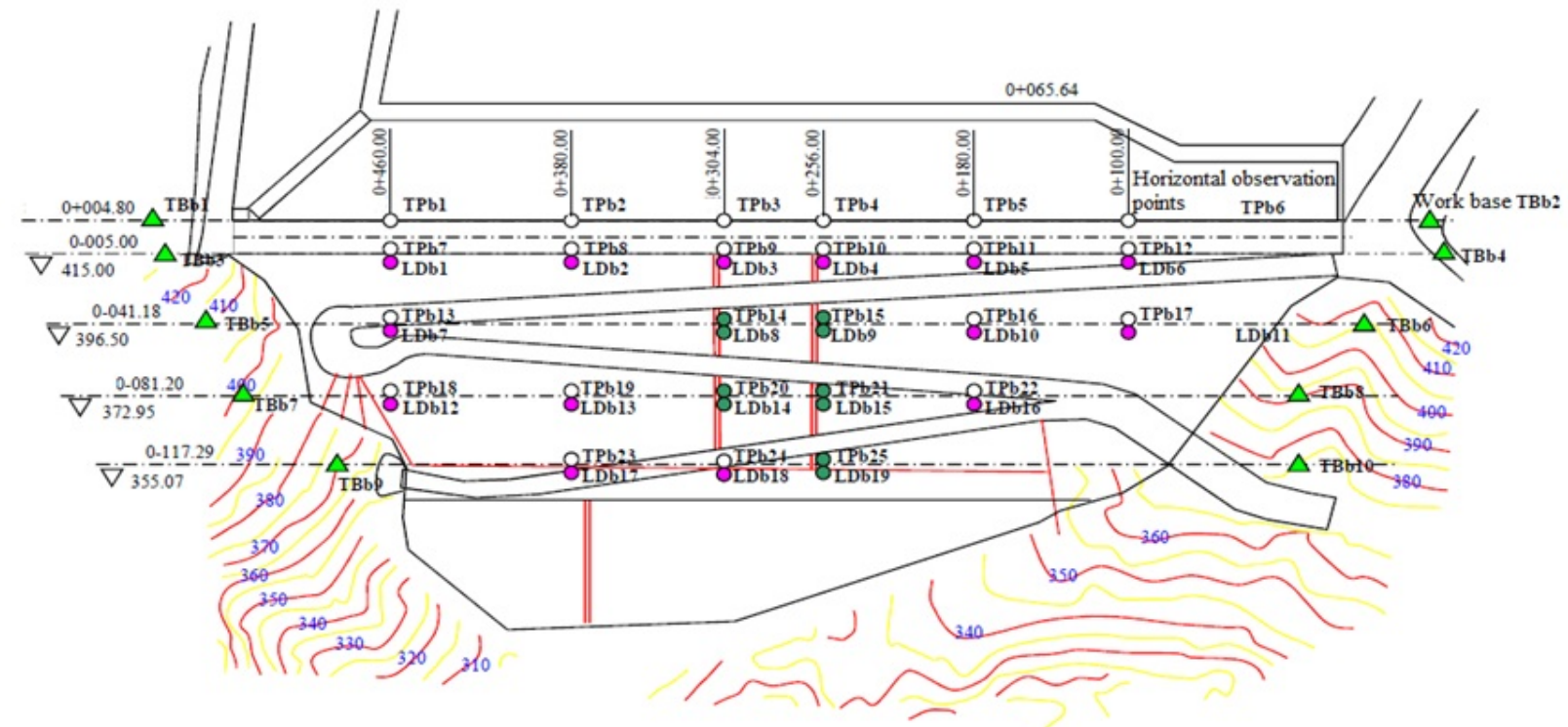

Fig. 7. Distribution of the external deformation observational instruments on the dam's body

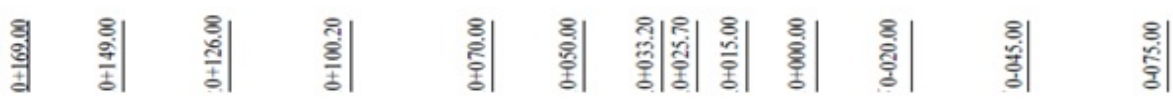

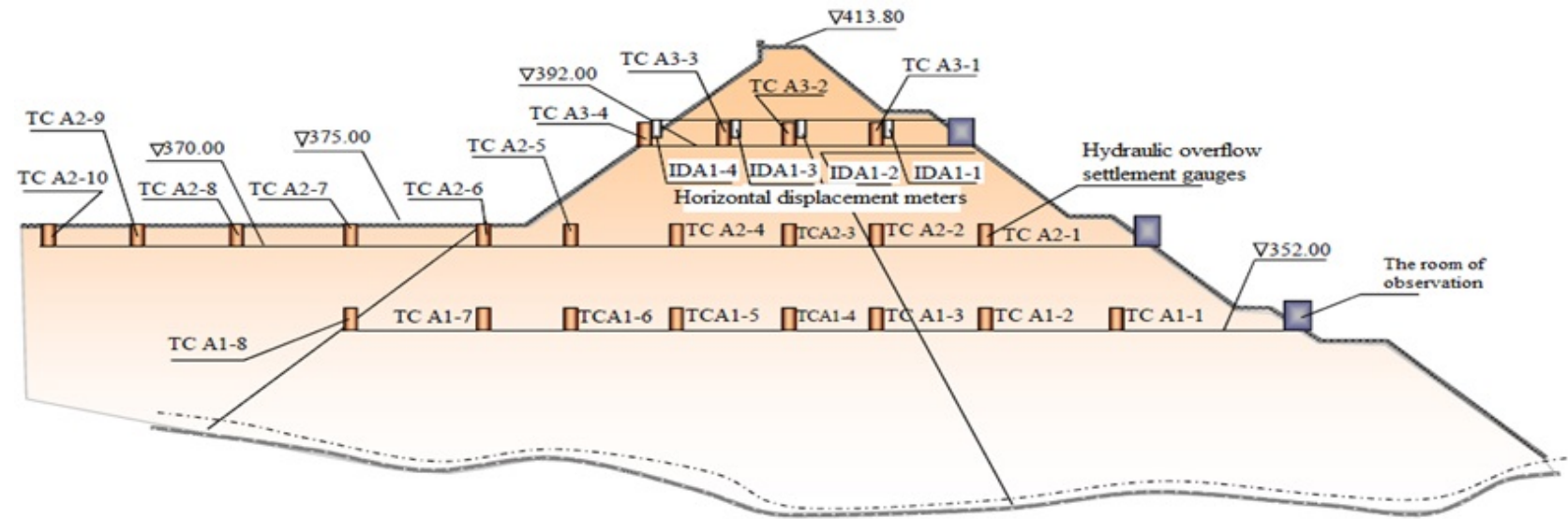

Fig. 8. Distribution of horizontal and vertical displacement meters on the dam's body (dam $0+255.91)$ 


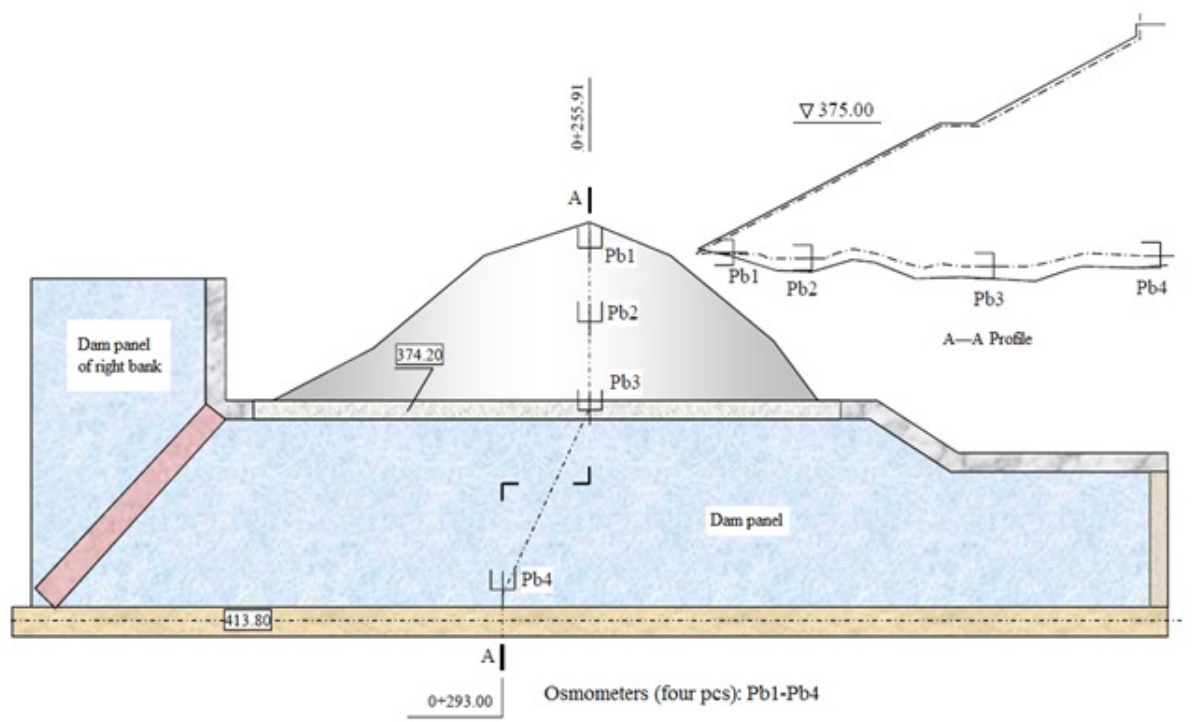

Fig. 9. Distribution of seepage pressure observational instruments at the dam's base

Table 6. Monitoring indexes for the appearance subsidence deformation

\begin{tabular}{|c|c|c|c|c|}
\hline Monitoring points & $y_{\max }$ & $S$ & $2 S$ & $3 S$ \\
\hline$L D b 1$ & 79.11 & 13.15 & 26.3 & 39.45 \\
\hline$L D b 2$ & 139.91 & 23.53 & 47.06 & 70.59 \\
\hline$L D b 3$ & 177.29 & 28.84 & 57.68 & 86.52 \\
\hline$L D b 4$ & 174.11 & 28.18 & 56.36 & 84.54 \\
\hline$L D b 5$ & 113.51 & 18.87 & 37.74 & 56.61 \\
\hline$L D b 6$ & 47.49 & 8.27 & 16.54 & 24.81 \\
\hline$L D b 7$ & 11.1 & 1.71 & 3.42 & 5.13 \\
\hline$L D b 8$ & 135.81 & 23.14 & 46.28 & 69.42 \\
\hline$L D b 9$ & 128.72 & 21.57 & 43.14 & 64.71 \\
\hline$L D b 10$ & 70.83 & 11.86 & 23.72 & 35.58 \\
\hline$L D b 11$ & 24.15 & 3.66 & 7.32 & 10.98 \\
\hline$L D b 12$ & 13.77 & 2.42 & 4.84 & 7.26 \\
\hline$L D b 13$ & 52.89 & 9.72 & 19.44 & 29.16 \\
\hline$L D b 14$ & 79.41 & 13.36 & 26.72 & 40.08 \\
\hline$L D b 15$ & 62.73 & 10.71 & 21.42 & 32.13 \\
\hline$L D b 16$ & 10.6 & 4.01 & 8.02 & 12.03 \\
\hline$L D b 17$ & 6.6 & 0.94 & 1.88 & 2.82 \\
\hline$L D b 18$ & 40.98 & 5.84 & 11.68 & 17.52 \\
\hline$L D b 19$ & 38.04 & 4.67 & 9.34 & 14.01 \\
\hline
\end{tabular}

Table 7. Safety degrees of the evaluation indexes of the dam body and dam base

\begin{tabular}{c|c|c|c|c|c}
\hline Evaluation indexes & Settlement & $\begin{array}{c}\text { Horizontal } \\
\text { displacement }\end{array}$ & Osmotic pressure & Deformation & Seepage \\
\hline Safety degree & 0.823 & 0.821 & 0.807 & 0.860 & 0.910 \\
\hline
\end{tabular}

Table 8. Weights of the evaluation indexes of the dam body and dam base

\begin{tabular}{c|c|c|c}
\hline $\begin{array}{c}\text { Evaluation } \\
\text { indexes }\end{array}$ & $\begin{array}{c}\text { Subjective } \\
\text { weight }\end{array}$ & $\begin{array}{c}\text { Objective } \\
\text { weight }\end{array}$ & $\begin{array}{c}\text { Combination } \\
\text { weights }\end{array}$ \\
\hline $\begin{array}{c}\text { Settlement } \\
\text { Horizontal } \\
\text { displacement }\end{array}$ & 0.293 & 0.177 & 0.232 \\
Osmotic & 0.205 & 0.176 & 0.184 \\
pressure & 0.267 & 0.169 & 0.214 \\
$\begin{array}{c}\text { Deformation } \\
\text { Seepage }\end{array}$ & 0.128 & 0.215 & 0.173 \\
\hline
\end{tabular}

The cloud membership of the safety assessment for the "dam body and dam base" was calculated using the concepts introduced in Sections 3.4.1 and 3.4.2. The results are presented in Table. 9.

The data in Tables 8 and 9 were calculated using Eq. (19) to determine the comprehensive cloud membership between the "dam body and dam base" and the evaluation grades (Table. 10).
Table 9. Cloud membership of the safety assessment for the dam body and dam base

\begin{tabular}{c|c|c|c|c|c}
\hline & $\mathbf{1}$ & $\mathbf{2}$ & $\mathbf{3}$ & $\mathbf{4}$ & $\mathbf{5}$ \\
\hline $\begin{array}{c}\text { Settlement } \\
\text { Horizontal } \\
\text { displacement }\end{array}$ & 0.663 & 0.351 & 0 & 0 & 0 \\
$\begin{array}{c}\text { Osmotic } \\
\text { pressure }\end{array}$ & 0.55 & 0.453 & 0 & 0 & 0 \\
$\begin{array}{c}\text { Deformation } \\
\text { Seepage }\end{array}$ & 0.895 & 0.17 & 0 & 0 & 0 \\
\hline
\end{tabular}

Table 10. Comprehensive cloud membership

\begin{tabular}{c|c|c|c|c|c}
\hline $\begin{array}{c}\text { Grade of } \\
\text { evaluation }\end{array}$ & $\mathbf{1}$ & $\mathbf{2}$ & $\mathbf{3}$ & $\mathbf{4}$ & $\mathbf{5}$ \\
\hline $\begin{array}{c}\text { Comprehensive } \\
\text { cloud } \\
\text { membership }\end{array}$ & 0.741 & 0.284 & 0 & 0 & 0 \\
\hline
\end{tabular}

The state eigenvalue ( $R^{\prime}$ ) of the samples was determined as 1.28 according to Eq. (20). The safety evaluation grades of the earth-rock dam indicated that the "dam body and dam base" are between normal and basically normal. The membership cloud for the "dam body and dam base" was 
Han Liwei, Liu Mingkai, Zhang Hongyang, Yao Liang and Ge Wei/

Journal of Engineering Science and Technology Review 12 (4) (2019) 38 - 50

generated and compared with the conceptual cloud model of the evaluation grade. The result showed that the evaluation grade is closest to Grade 1 (i.e., normal) (Fig. 10).

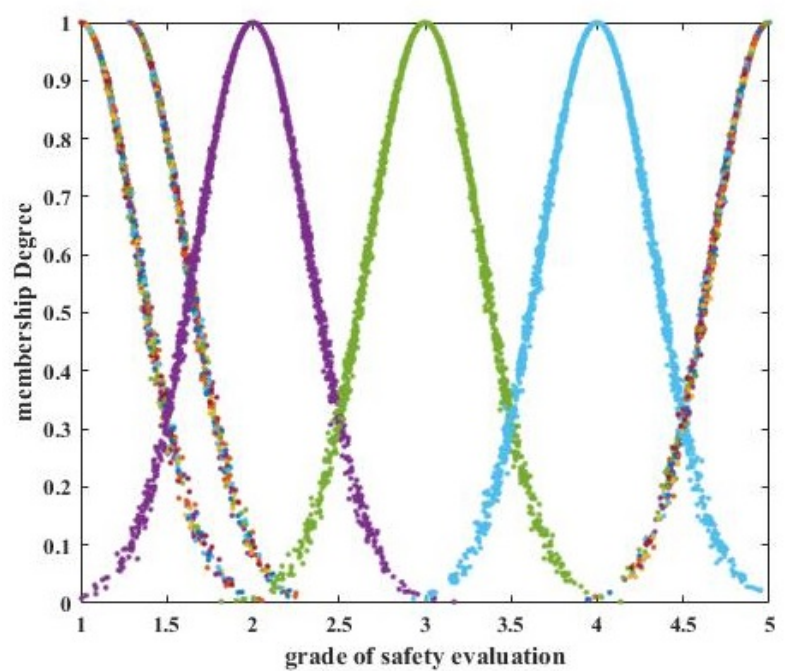

Fig. 10. Comprehensive evaluation cloud at dam's body and foundation level

\section{Conclusions}

Earth-rock dams are multiparameter, nonlinear, and timevarying unstable systems that exhibit many uncertainties. Two of the uncertainties identified in this study are randomness and fuzziness, which are involved in the safety assessment process of earth-rock dams. A safety assessment method for earth-rock dams based on cloud theory is proposed in this study to solve this problem. The validity and feasibility of the proposed method are verified through a case study. The following major conclusions can be drawn:

(1) The proposed safety assessment method of earth-rock dam based on cloud theory can effectively solve fuzziness and randomness problems and accurately reflect the dam's operational state.

(2) Weight problems among different evaluation indexes are considered. Subjective and objective weights are combined through weighting method based on ideal point. This method reflects subjectivity and eliminates randomness in the interference information. Accordingly, the calculated combination weights are real and reliable.

(3) The safety assessment model is verified through a case study. Result showed that the evaluations are consistent with the actual running state. This model provides a new method for the safety assessment of earth-rock dams.

The proposed safety assessment model is based on the randomness and fuzziness of earth-rock dams. The evaluation results of the model can reflect the actual operational state of earth-rock dams more accurately than traditional methods and provide a new method for the dynamic health assessment of dams. However, other uncertainties exist, including gray, unknown, and chaos, remain. Therefore, further deep studies on establishing a health diagnosis system that considers many uncertainties are needed.

\section{Acknowledgements}

The authors are grateful for the support provided by the National Key R\&D Program of China (Nos. 2017YFC1501201 \& 2018YFC0406803), National Natural Science Foundation of China (No. 51509091), and Support Plan of Scientific and Technological Innovation Team in several colleges and universities in Henan Province (No. 19IRTSTHN030)

This is an Open Access article distributed under the terms of the Creative Commons Attribution License

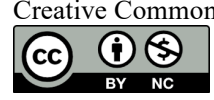

\section{References}

1. Su, H., Li, J., Wen, Z., Guo, Z., Zhou, R., "Integrated certainty and uncertainty evaluation approach for seepage control effectiveness of a gravity dam". Applied Mathematical Modelling, 65, 2019, pp.1-22.

2. Baecher, G. B., "Uncertainty in dam safety risk analysis". Georisk: Assessment and Management of Risk for Engineered Systems and Geohazards, 10(2), 2016, pp.92-108.

3. Xiong, W., Tian, Bo., lu, J. H., "Discussion on technologies and methods of safety evaluation of dams and reservoirs". Yangtze River, 42(12), 2011, pp.24-27.

4. Ding, Y. H., Yuan, H. N., Zhang B. Y., Yu, Y. Z., "Stressdeformation characteristics of super-high central core rock-fill dams". Journal of Hydroelectric Engineering, 32(4), 2013, pp.153-158.

5. Chen, S. S., Yan, Z. K., Fu, Z. Z., Li, G. Y., "Evaluation of safety performance of extremely high slab-faced gravel dams". Chinese Journal of Geotechnical Engineering, 39(11), 2017, pp.19491958.

6. Rashidi, M., Haeri, S. M., "Evaluation of behaviors of earth and rockfill dams during construction and initial impounding using instrumentation data and numerical modeling". Journal of Rock Mechanics and Geotechnical Engineering, 9(4), 2017, pp.709725.

7. Min, H. E., Kuang, J. J., Zhao, X. G., "The safety assessment of an earth core dam base on in-situ measurement and back analysis". In: 2018 2nd International Workshop on Renewable Energy and Development. Guilin, China: GSRA, 2018, pp.052055.
8. Wei, H., Yang, H. S., Wu, L., Gui, Y., "Dam Safety Reliability Analysis Based on Artificial Neural Network". In: 2011 International Conference on Civil Engineering and Building Materials. Kunming, China: IASHT, 2011, pp.3620-3625.

9. Liu, H. F., Ren, C., Zheng, Z. T., Liang, Y. J., Lu, X. J., "Study of a gray genetic BP neural network model in fault monitoring and a diagnosis system for dam safety". ISPRS International Journal of Geo-Information, 7(1), 2017, pp.4.

10. Li, H., Ouyang, J., Li, F., Xie, X., "Study on safety evaluation model of small and medium-sized earth-rock dam based on BPAdaBoost algorithm". In: 2nd International Symposium on Application of Materials Science and Energy Materials. Shanghai, China: CUP, 2018, pp.032024.

11. Kucukali, S., "Risk assessment of river-type hydropower plants using fuzzy logic approach". Energy Policy, 39(10), 2011, pp.6683-6688.

12. Fu, X., Gu, C. S., Su, H. Z., Qin, X. N., "Risk analysis of earthrock dam failures based on fuzzy event tree method". International journal of environmental research and public health, 15(5), 2018, pp.886.

13. Peng, H., Liu, D., Tian, B., Zuo, J., "Study on the comprehensive safety assessment of earth fill dam based on AHP methods". In: 16th Congress of Asia and Pacific Division of IAHR. Nanjing, China: IAHR, 2008, pp.1848-1853.

14. Zheng, X., Gu, C., Qin, D., "Dam's risk identification under interval-valued intuitionistic fuzzy environment". Civil Engineering and Environmental Systems, 32(4), 2015, pp.351363 . 
Han Liwei, Liu Mingkai, Zhang Hongyang, Yao Liang and Ge Wei/

Journal of Engineering Science and Technology Review 12 (4) (2019) 38 - 50

15. Ji, Y., Huang, G. H., Sun, W., "Risk assessment of hydropower stations through an integrated fuzzy entropy-weight multiple criteria decision making method: A case study of the Xiangxi River". Expert Systems with Applications, 42(12), 2015, pp.53805389 .

16. Li, D., Du, Y., “Artificial intelligence with uncertainty”. Florida: CRC press, America, 2017, pp.34-36.

17. Li, Z. K., Jiang, J. S., Wang, G. Y., "Comprehensive assessment of observed behavior of earth-rockfill dams". Chinese Journal of Geotechnical Engineering, 29(2), 2007, pp.255-259.

18. Liang, L., Liu, Q., Li, M., "Dam-break risk assessment model of tailings reservoir based on variable weight synthesis and analytic hierarchy process". Journal of Northeastern University (Natural Science), 38(12), 2017, pp.1790-1794.

19. Rezaei, J., "Best-Worst Multi-Criteria Decision-Making Method". Omega, 53, 2015, pp.49-57.

20. Wang, T., Chen, J. S., Wang, T., "Entropy weight-set pair analysis (SPA) for dam leakage detection". Chinese Journal of Geotechnical Engineering, 36(11), 2014, pp.2135-2143.

21. Charnes, A., Cooper, W. W., Rhodes, E., "Evaluating program and managerial efficiency: an application of data envelopment analysis to program follow through". Management science, 27(6), 1981, pp.668-697.

22. Lin, Z., Wen, F., Wang, H., Lin, G., Mo, T., Ye, X., "CRITICbased node importance evaluation in skeleton-network reconfiguration of power grids". IEEE Transactions on Circuits and Systems II: Express Briefs, 65(2), 2018, pp.206-210.

23. Saaty, T. L., "How to make a decision: the analytic hierarchy process". European journal of operational research, 48(1), 1990, pp.9-26.
24. Huang, D. C., Xu, L., "Proportion criteria and method for building comparison matrices in the analytic hierarchy process". Control and decision, 17(4), 2002, pp.484-486.

25. Wang, J. Q., Zhao, T., "Design and Realization of a Fuzzy Evaluation Model for Software Quality Based on Entropy Weight". Computer \& Digital Engineering, 36(2), 2008, pp.29$30+109+169$

26. Jiang, Q., Fang, K., Zhang, G., "Assessment of geo-hazards risk based on new combined weight method". Journal of Natural Disasters, 24(3), 2015, pp.28-36.

27. Li, D. Y., Liu, C. Y., Gan, W. Y., "A new cognitive model: Cloud model". International Journal of Intelligent Systems, 24(3), 2009, pp.357-375.

28. The National Development and Reform Commission of The People's Republic of China. "Technical specification for dam safety monitoring automation" [EB/OL]. Retrieved from https://wenku.baidu.com/view/40f372befd0a79563c1e7233.html, 2005-02-14/2019-08-10.

29. Ministry of Water Resources of the People's Republic of China. "Fundamental specification of equipment of automation system for dam safety monitoring" [EB/OL]. Retrieved from https://www.docin.com/p-1750791632.html, 2001-06-14/201908-10.

30. Ministry of Water Resources of the People's Republic of China "Technical specification for earth-rockfill dam safety monitoring" [EB/OL]. Retrieved from https://max.book118.com/html/2017/0619/116671367.shtm, 2012-03-18/2019-08-10.

31. He, J. P., Li, Z. Z., Shi, Y. Q., "A study on comprehensive assessment method of dam structure monitoring behaviour". Journal of hydroelectric engineering, 20(2), 2001, pp.36-42. 